\title{
A rare case of intracranial malignant triton tumor arising in the middle cranial fossa: a case report and review of the literature
}

\author{
Eros Bruzzone ${ }^{1}$, Ilaria Melloni ${ }^{1}$, Salvina Barra ${ }^{2}$, Giulio Fraternali Orcioni ${ }^{3}$, Leonardo Cocito ${ }^{4}$ \\ ${ }^{1}$ Department of Neurosurgery, IRCCS San Martino University Hospital, Genoa, ${ }^{2}$ Department of Radiotherapic Oncology, IRCCS \\ San Martino University Hospital, Genoa, ${ }^{3}$ Department of Pathology, IRCCS San Martino University Hospital, Genoa, ${ }^{4}$ Department \\ of Neurological Sciences (DINOGMI), University of Genoa, Italy
}

\begin{abstract}
We describe a rare case of intracranial malignant triton tumor (MTT) arising in the middle cranial fossa in a 74-yearold female patient who had previously been exposed to radiation in the Chernobyl disaster. The patient underwent a surgical subtotal removal of the mass and radiation therapy, but the progression-free survival was only 2.5 months and death occurred four months after the onset of symptoms. MTTs are rare aggressive tumors arising from the nerve sheath showing rhabdomyosarcomatous differentiation and associated with a poor prognosis. The intracranial location is very rare, and only 10 cases, including the present report, have been described so far. Among intracranial MTTs, the cerebellopontine angle is the most common location. Neurofibromatosis type 1 (NF-1) and radiation exposure are risk factors as for MTTs located in other sites. The gold standard therapy is surgical excision followed by radiation therapy, but the prognosis is usually very poor.
\end{abstract}

Key words: malignant triton tumor (MTT), rare intracranial tumors, nerve sheath tumors.

\section{Introduction}

Malignant triton tumors (MTTs) are a rare subtype (accounting for less than 10\%) of malignant peripheral nerve sheath tumors (MPNSTs) showing rhabdomyosarcomatous differentiation and following a particularly aggressive clinical course [24]. In a recent metanalysis, only 124 cases of MTT were reported between 1973 and 2010 in the English and French literature [24]. Since then, 38 further cases of MTT have been reported [9,10,11,13-15,17,18,20,
22,25-27,31-34], of whom only few had an intracranial location $[1,3,6,7,11,12,19,34,35]$. About one half of cases are related to neurofibromatosis type 1 (NF-1), and previous exposure to radiation is a recognized risk factor [37].

We describe a rare case of intracranial malignant triton tumor, probably arising from the left oculomotor nerve sheath, which eroded the middle cranial fossa and progressed into the infratemporal fossa. To our knowledge, only nine intracranial cases have been reported so far $[1,3,6,7,11,12,19,34,35]$. 


\section{Case report}

A 74-year-old woman presented to the Emergency Unit for left facial pain and blush, strabismus with diplopia, left mydriasis and ptosis. Her remote history was irrelevant, apart from reporting exposure to radiation during the Chernobyl nuclear disaster in 1986. Indeed, she was living at the time in a rural Ukrainian area northern of Kiev, where she remained until she moved to Western Europe in about 2000.

An emergent computed tomography (CT) scan revealed an extremely large intra-extracranial petroclival lesion, extending from the middle cranial fossa into the infratemporal fossa through a wide skull erosion (Fig. 1).

Cranial magnetic resonance imaging (MRI) confirmed the presence of the lesion, which was well delimited from the brain, hyperintense in $\mathrm{T} 2$ and inhomogeneously contrast enhanced (Fig. 2).

The patient underwent surgery and a subtotal removal of the intracranial component of the neoplasm was performed. After the surgery, facial pain disappeared and she could quickly resume her previous activities.

Histology revealed a high-grade sarcoma (FNCLCC grade 3) with necrosis, neoplastic areas with positivity

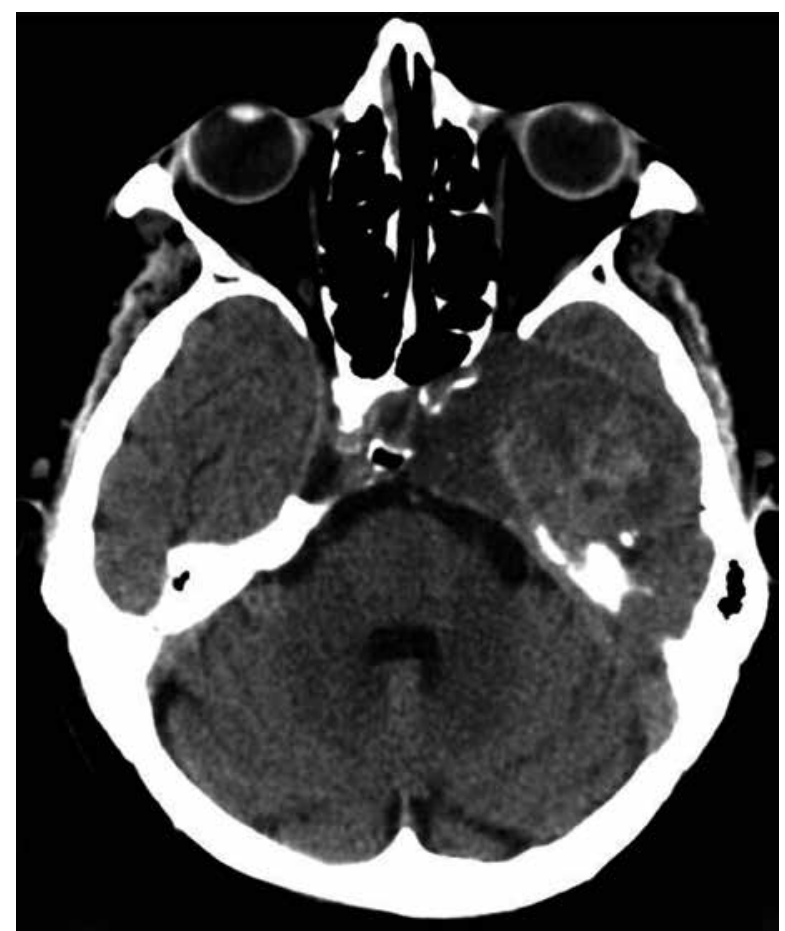

Fig. 1. Unenhanced axial CT scan showing a large mass in the left middle cranial fossa. for S100, heterologous osteocartilaginous areas and skeletal muscular differentiation (positive stain for desmin and myogenin). In conclusion, histology disclosed an intracranial MPNST with skeletal muscle differentiation (the so-called MTT) (Fig. 3).

MPNST arising from a peripheral nerve may be associated with a pre-existing benign nerve sheath tumor, or may occur in patients with NF-1. When, as in this case, these aspects are absent, the diagnosis is based on the constellation of histological and immunohistochemical features.

Despite the close relation between MTT and NF-1, no genetic studies were performed because of the absence of any other stigmata of the disease, such as café-au-lait spots, axillary freckling, Lisch nodules, cutaneous neurofibromas, optic glioma or familiarity for NF-1. No synchronous metastases were shown at a full-body radiologic examination.

The patient underwent adjuvant conformational radiotherapy at a total dose of 50 Gy scheduled in 20 sessions, while no chemotherapy was proposed. Despite the treatment, the progression-free survival was only 2.5 months and the overall survival was 4 months.

\section{Discussion}

MTT is a rare, aggressive subtype of MPNSTs with rhabdomyosarcomatous differentiation and poor prognosis [15]. This tumor was first described by Masson in 1932 in neurofibromatosis patients [23], but it received this name in 1973 [39], basing on the previous observation that triton salamander can generate supernumerary limbs, formed by striated muscle, bone and nervous tissue if sciatic nerve is implanted on its back [21].

Most reported cases are diagnosed in the middle age (30-50 years) [15,24]; although a male predominance has been reported [15], this finding is not confirmed by the largest metanalysis [24].

MTTs, as MPNSTs, may arise either de novo or in the context of a previous benign schwannoma [36]. The most widely accepted explanation for their occurrence is that Schwann cells, which arise from the neural crest, may retain some capacity of differentiating in mesenchymal components during neoplastic transformation [41].

Diagnostic criteria proposed originally for MTT were as follows: 1 ) the tumor arises along a peripheral nerve, or in the context of a ganglioneuroma, 


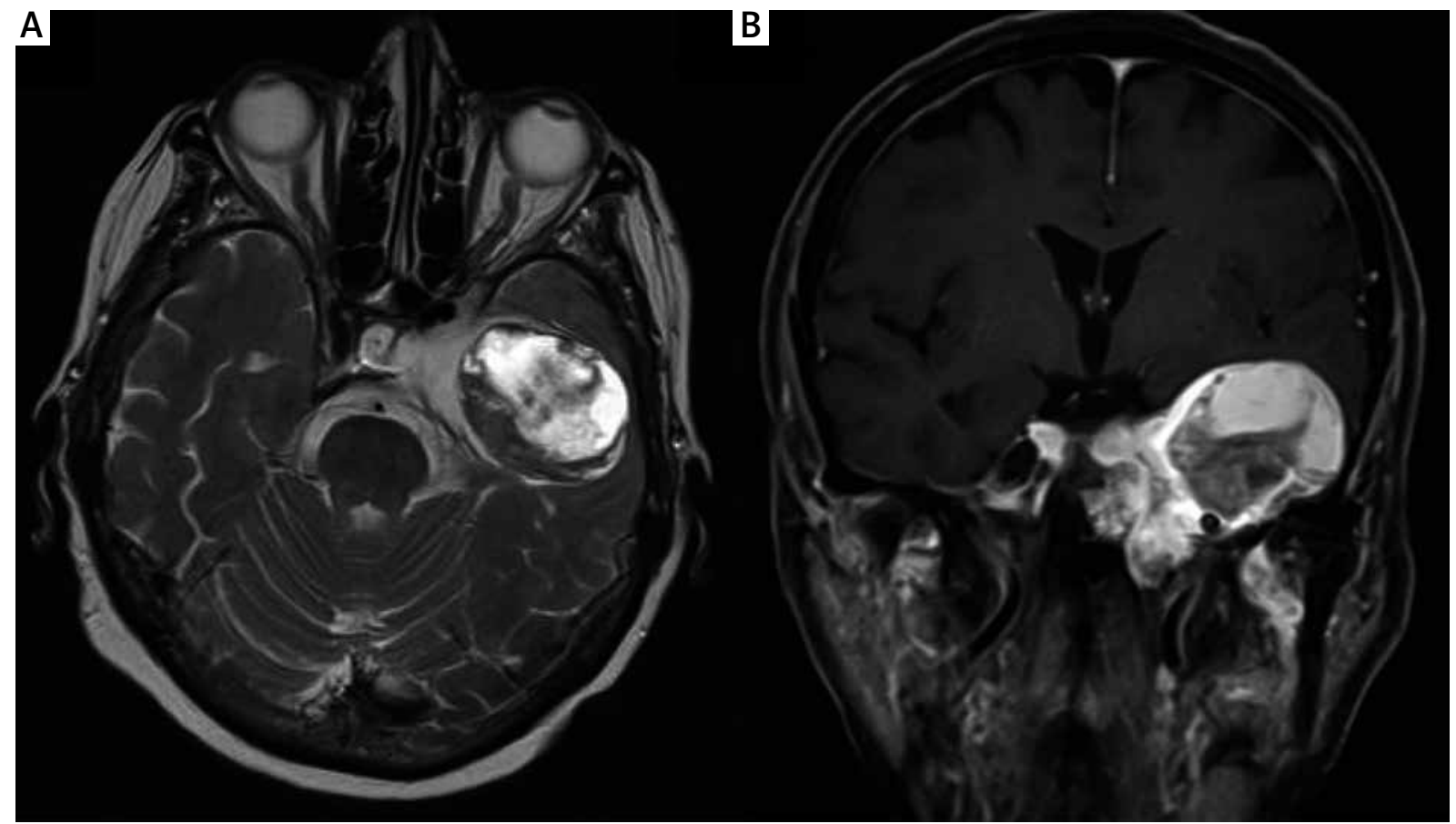

Fig. 2. MR Imaging. A) Axial T2-weighted MRI showing an inhomogeneous mass in the left middle cranial fossa, strictly adherent to the left cavernous sinus, causing a mass effect on the temporal lobe. B) Enhanced coronal T1-weighted MRI showing an inhomogeneously enhancing lesion, which erodes the skull base and invades the infratemporal fossa.

or in an NF-1 patient, 2) it has the characteristics of growth of a Schwann cell tumor, 3) rhabdomyoblasts can be demonstrated inside the tumor [39]. Nowadays, immunohistochemistry stains with positivity for \$100, myoglobin, desmin, muscle-specific actin, sarcomeric actin and myogenin, as skeletal muscle markers, are essential for diagnosis [30].

NF-1 association is reported in $38-57 \%$ of cases $[24,40]$. Previous radiation exposure is reported in $8 \%$ of patients with MTT [24] and it is a recognized risk factor [2]. Moreover, even therapeutic irradiation can be a trigger to MTT formation: in fact, malignant progression from benign schwannoma to MTT following the radiation therapy has been reported [29]. Indeed, one case of progression of a vestibular schwannoma to a malignant triton tumor after stereotactic radiosurgery has been reported [6]. The relationship between radiation and Schwann cell transformation has been previously investigated: it is recognized that small doses of radiation may alter the architecture of this cell line [4], therefore inducing loss of chromosomal stability and transformation [5]. It has been postulated that radiation- induced MTTs occur 4 to 41 years after irradiation, due to the very slow turnover in peripheral nerve sheath [29].

MTTs usually present in the head, trunk and extremities, more rarely they occur in retroperitoneum, vertebral column and within the heart [15]. The previously reported finding, that head and neck location had a better prognosis [37], has not been confirmed by more recent studies [15].

The gold standard therapy is wide surgical excision, of course whenever possible, followed by the adjuvant radiation therapy [24]. There is no evidence of the effectiveness of chemotherapy; however, chemotherapeutic regimens such as PEI (cisplatin, etoposide, ifosfamide) as the first-line chemotherapy and IA (ifosfamide, adriamycin) or MAID (mesna, doxorubicin, ifosfamide and dacarbazine) have been proposed as the second-line treatment [38]. Favorable response to treatment with isotretinoin (a retinoid analogue) and interferon $\alpha$ were also reported, in cases in which retinoic acid receptors were present in the tumor specimen [16]. 

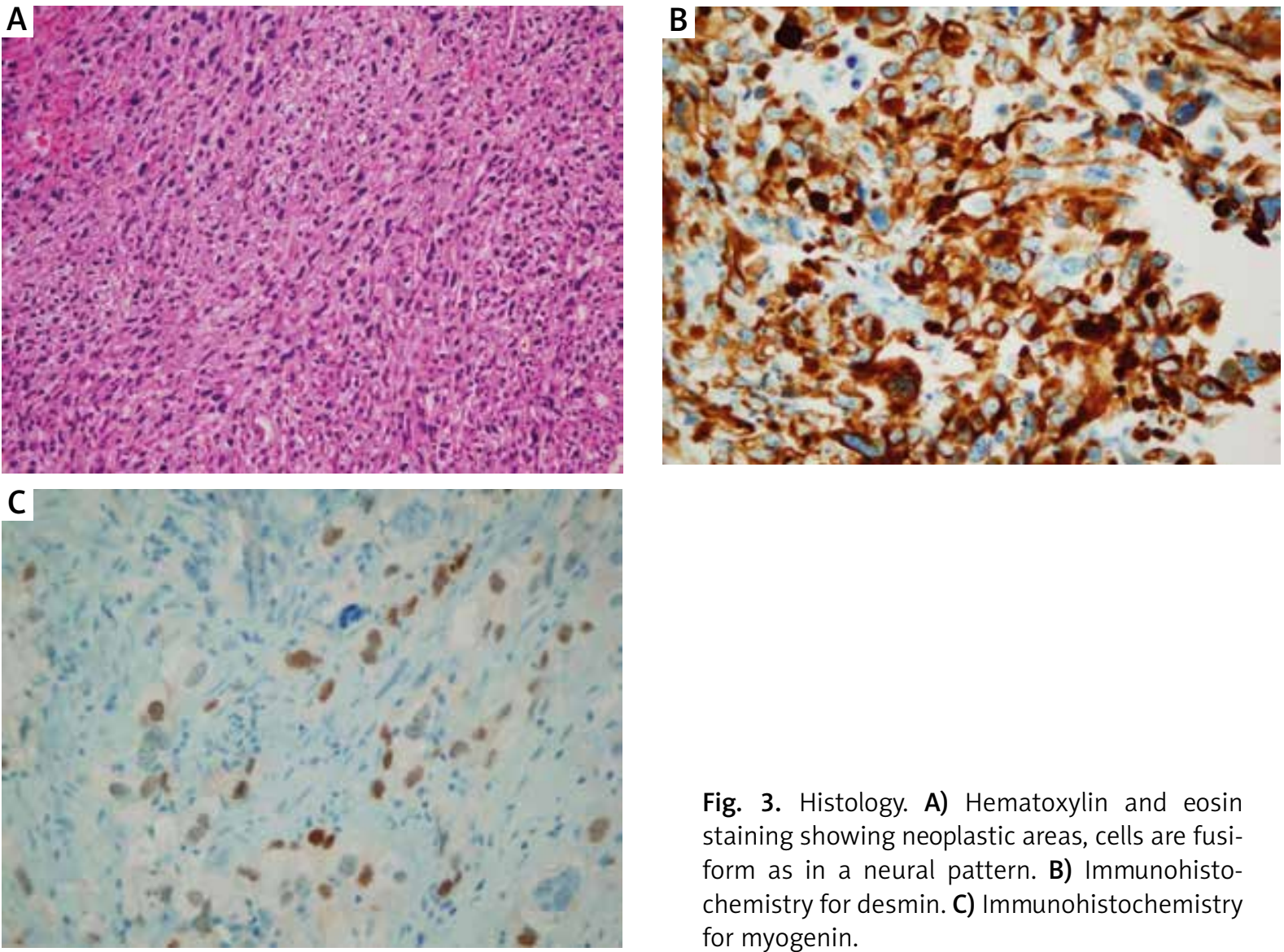

Fig. 3. Histology. A) Hematoxylin and eosin staining showing neoplastic areas, cells are fusiform as in a neural pattern. B) Immunohistochemistry for desmin. C) Immunohistochemistry for myogenin.

Table I. Summary of reports of intracranial malignant triton tumors (MTTs)

\begin{tabular}{|lccccl|}
\hline Authors & Age & Sex & NF-1 & $\begin{array}{c}\text { Previous } \\
\text { radiation }\end{array}$ & Site of MTT \\
\hline Best, 1987 [1] & 24 & F & No & No & Cerebellopontine angle \\
\hline Bornstein-Quevedo et al., 2003 [3] & 3 & M & No & No & Parieto-occipital \\
\hline Comey et al., 1998 [6] & 44 & M & No & Yes & Cerebellopontine angle \\
\hline De Cauwer et al., 2007 [7] & 57 & M & Yes & No & Rolandic \\
\hline Gong et al., 2012 [11] & 55 & M & No & No & Cerebellopontine angle \\
\hline Han et al., 1992 [12] & 47 & F & No & No & Cerebellopontine angle \\
\hline Lau et al., 2010 [19] & 42 & M & No & No & Nasal cavity - cribriform plate \\
\hline Smith et al., 2014 [34] & 26 & F & Yes & No & Bifrontal \\
\hline Takahashi et al., 2000 [35] & 57 & M & Yes & No & Lateral ventricle \\
\hline
\end{tabular}

The outcome of MTT is generally poor. 5-year overall survival is only $14 \%$, and median time to death is 13 months [24]. Distant metastases develop in about one third of cases, local progression or recurrence occur in $50 \%$, and median time to recurrence/progression is 6 months [24].
Most important unfavorable prognostic factors are association with NF-1, age, size, presence of positive margins at surgery or histological examination, and location of the tumor in the trunk [15,24].

Intracranial MTTs have seldom been reported. Only nine cases were reported from 1987 to 2014 
[1,3,6,7,11,12,19,34,35] (Table I). Mean patient age at diagnosis was 39 years, ranging from 3 to 57 , and most patients were males (6/9). NF-1 association was found in only one third (3/9) of patients; previous radiation exposure was reported in one case, specifically represented by a MTT arising at the site of a vestibular schwannoma after stereotactic radiosurgery [6]. The cerebellopontine angle was the most common site of origin (4/9); in four cases, however, MTT seemed to arise directly from brain parenchyma.

Our case is the first MTT ever reported developing in the middle cranial fossa, extending towards the petroclival region and eroding the skull base to invade the infratemporal fossa, and probably arising from the third nerve sheath. Previous intense radiation exposure during the Chernobyl disaster, about 30 years prior to tumor presentation, might be considered as a trigger for neoplastic transformation. Precise details on the patient's actual radiation exposure are not available, but most reliable information would indicate that, during the first 10 years after the accident, average effective doses of exposure in the neighboring areas ranged from $5 \mathrm{mSv}$ (the reported level for Russian urban areas) to $11 \mathrm{mSv}$ (the reported level for the rural areas of the Ukraine where the patient was living at the time and spent about 15 further years after the nuclear accident) $[8,28]$.

\section{Conclusions}

In this report, we describe a rare case of intracranial MTT. To the best of our knowledge, it is the tenth case reported in the literature. Although very rare, intracranial MTTs are very aggressive tumors arising in young or middle-aged patients, often associated with NF-1 and a poor prognosis. Previous radiation exposure is a recognized risk factor as confirmed by our case.

\section{Disclosure}

The authors declare no conflict of interest.

\section{References}

1. Best PV. Malignant triton tumour in the cerebellopontine angle. Report of a case. Acta Neuropathol 1987; 74: 92-96.

2. Beuvon F, Criscuolo JL, Salmon RJ, Laurent M. Neurosarcome radio-induit. Aspects clinique, histologique et immunohistochimique. Bull Cancer 1991; 78: 619-626.
3. Bornstein-Quevedo L, Peralta-Olvera F, Marhx-Bracho A, Rodríguez-Jurado R, De Leon-Bojorge B. Cerebral malignant nerve sheath tumor, triton tumor variant: case report. Pediatr Dev Pathol 2003; 6: 168-172.

4. Cavanagh JB. Effects of $x$-irradiation on the proliferation of cells in peripheral nerve during Wallerian degeneration in the rat. Br J Radiol 1968; 41: 275-281.

5. Coffin CM, Dehner LP. Peripheral neurogenic tumors of the soft tissues in children and adolescents: a clinicopathologic study of 139 cases. Pediatr Pathol 1989; 9: 387-407.

6. Comey CH, McLaughlin MR, Jho HD, Martinez AJ, Lunsford LD. Death from a malignant cerebellopontine angle triton tumor despite stereotactic radiosurgery. Case report. I Neurosurg 1998; 89: 653-658.

7. De Cauwer H, Bogers JP, Duwel V, den Hauwe V, Croese P, Van Marck E An intracerebral intraparenchymatous triton tumor in a man with neurofibromatosis J Neurol 2007; 254: 1009-1011.

8. Drozdovitch V, Bouville A, Chobanova N, Filistovic V, Ilus T, Kovacic M, Malátová I, Moser M, Nedveckaite T, Völkle H, Cardis E. Radiation exposure to the population of Europe following the Chernobyl accident. Radiat Prot Dosimetry 2007; 123: 515-528.

9. Engel EE, Brassesco MS, Valera ET, Nogueira-Barbosa MH, Yamashita ME, Scrideli CA, Tone LG. Clinico-genetic aspects of a pediatric non-neurofibromatosis type 1 malignant triton tumor with loss of chromosome X. Pediatr Blood Cancer 2012; 59: 1320-1323.

10. Ghosh A, Sastri SB, Srinivas D, Mahadevan A, Anandappa CB, Shankar SK. Malignant triton tumor of cervical spine with hemorrhage. J Clin Neurosci 2011; 18: 721-723.

11. Gong L, Liu XY, Zhang WD, Han XJ, Yao L, Zhu SJ, Lan M, $\mathrm{Li} Y \mathrm{YH}$, Zhang W. A rare case of malignant triton tumor in the cerebellopontine angle. Diagn Pathol 2012; 7: 43.

12. Han DH, Kim DG, Chi JG, Park SH, Jung HW, Kim YG. Malignant triton tumor of the acoustic nerve. Case report. J Neurosurg 1992; 76: 874-877.

13. Jaing TH, Chuang CC, Jung SM, Wu CT, Tseng CK, Chen CS. Malignant triton tumor of the cervical spine: report of one case and review of the literature. Pediatr Neonatol 2015; 56: 58-61.

14. Kamperis E, Barbetakis N, Asteriou C, Kleontas A, Christoforidou V. Malignant triton tumor of the chest wall invading the lung. A case report and literature review. Hippokratia 2013; 17: $277-280$.

15. Kamran SC, Howard SA, Shinagare AB, Krajewski KM, Jagannathan JP, Hornick JL, Ramaiya NH. Malignant peripheral nerve sheath tumors: prognostic impact of rhabdomyoblastic differentiation (malignant triton tumors), neurofibromatosis 1 status and location. Eur J Surg Oncol 2013; 39: 46-52.

16. Köstler WJ, Amann G, Grunt TW, Singer CF, Schneider SM, Brodowicz T, Tomek S, Zielinski CC. Recurrent malignant Triton tumour: first report on a long time survivor. Oncol Rep 2003; 10: 533-535.

17. Koutsimpelas D, Brieger J, Heinrich U, Torzewski M, Sommer C, Mann WJ. Cytogenetic analysis of a malignant triton tumour by comparative genomic hybridization (CGH) and review of the literature. Eur Arch Otorhinolaryngol 2011; 268: 1391-1396.

18. Koutsopoulos AV, Mantadakis E, Katzilakis N, Lagoudaki ED, de Bree E, Stiakaki E, Kalmanti M. Long-term survival of 
a patient with a neurofibromatosis type 1 associated retroperitoneal malignant triton tumor after multi-modality treatment. Clin Neuropathol 2011; 30: 333-335.

19. Lau OD, Nabili V, Lai C, Kirsch CF, Tantiwongkosi B, Abemayor E. Pathology quiz case 1. Diagnosis: Sinonasal malignant Triton tumor (MTT) with intracranial extension. Arch Otolaryngol Head Neck Surg 2010; 136: 929, 931.

20. Li Z, Xiang J, Yan S, Gao F, Zheng S. Malignant triton tumor of the retroperitoneum: a case report and review of the literature. World J Surg Oncol 2012; 10: 96.

21. Locatelli P. Formation de membres surnuméraires. C R Assoc Anat 20e Reunion, Turin 1925; 279-282.

22. Mae K, Kato Y, Usui K, Abe N, Tsuboi R. A case of malignant peripheral nerve sheath tumor with rhabdomyoblastic differentiation: malignant triton tumor. Case Rep Dermatol 2013; 5: 373-378.

23. Masson P. Recklinghausen's neurofibromatosis, sensory neuromas and motor neuromas. In: Emanuel Libman Anniversary. Vol. 2. International Press, New York 1932; 793-802.

24. McConnell YJ, Giacomantonio CA. Malignant triton tumors complete surgical resection and adjuvant radiotherapy associated with improved survival. Surg Oncol 2012; 106: 51-56.

25. Mijović Z, Mihailović D, Zivković N, Kostov M, Zivković S, Stojanović N. A rare case of retroperitoneal malignant Triton tumor invading renal vein and small intestine. Vojnosanit Pregl 2013 70: $322-325$.

26. Nirhale DS, Parasnis A, Bora C, Gupta R, Aulakh P. Retroperitoneal peripheral nerve sheath tumour of triton type - a case report. Indian J Surg 2013; 75 (Suppl 1): 12-14.

27. Nitsche $M$, Reible $M$, Pflüger KH, Bergmann M, Hermann RM. Malignant triton tumor of the sciatic nerve as a secondary malignancy after extended field radiotherapy and chemotherapy of Hodgkin's disease. Case Rep Oncol 2014; 7: 239-245.

28. Nuclear Energy Agency. Chernobyl: Assessment of Radiological and Health Impacts. 2002 Update of Chernobyl: Ten Years On. Chapter IV: Doses Estimates. NEA-OECD, Paris 2002; 61-75.

29. Ozer E, Erkilic S, Bayazit YA, Mumbuc S, Aydin A, Kanlikama M. Malignant triton tumor of the supraclavicular region arising after radiotherapy. Auris Nasus Larynx 2002; 29: 405-407.

30. Parham DM. Pathologic classification of rhabdomyosarcomas and correlations with molecular studies. Mod Pathol 2001; 14 506-514.

31. Prieto R, Pascual JM, García-Cabezas MA, López-Barea F, Barrios L, González-Llanos F. Low-grade malignant triton tumor in the lumbar spine: a rare variant of malignant peripheral nerve sheath tumor with rhabdomyoblastic differentiation. Neuropathology 2012; 32: 180-189.

32. Ren W, Xu X, Yan J, Qian X, Liu B. Malignant triton tumor of the anterior mediastinum: a case report. Oncol Lett 2014; 7: 807810.

33. Shetty PK, Baliga SV, Balaiah K. Malignant triton tumor: a rare case. Indian J Surg 2013; 75 (Suppl 1): 362-365.

34. Smith RE, Kebriaei MA, Gard AP, McComb RD, Bridge JA, Lennarson PJ. Intracranial malignant triton tumor in a patient with neurofibromatosis type 1: case report and review of the literature. Brain Tumor Pathol 2014; 31: 149-154.
35. Takahashi Y, Sugita Y, Abe T, Yuge T, Tokutomi T, Shigemori M. Intraventricular malignant triton tumour. Acta Neurochir (Wien) 2000; 142: 473-476.

36. Tanimura A, Nagayama K, Nishimura T. Malignant schwannoma associated with embryonal rhabdomyoblastic foci in a single tumor. Acta Pathol Jpn 1984; 34: 133-138.

37. Terzic A, Bode B, Gratz KW, Stoeckli SJ. Prognostic factors for the malignant triton tumor of the head and neck. Head Neck 2009; 31: 679-688.

38. Thoennissen NH, Schliemann C, Brunnberg U, Schmidt E, Staebler A, Stegger L, Bremer C, Schleicher C, Mesters RM, MüllerTidow C, Berdel WE. Chemotherapy in metastatic malignant triton tumor: report on two cases. Oncol Rep 2007; 18: 763-767.

39. Woodruff JM, Chernik NL, Smith MC, Millett WB, Foote FW. Peripheral nerve tumors with rhabdomyosarcomatous differentiation (malignant “Triton” tumors). Cancer 1973; 32: 426-439.

40. Woodruff JM, Kourea HP, Louis DN, Scheithauer BW. Malignant peripheral nerve sheath tumor (MPNST). In: Kleihues P, Cavenee WK (eds.). Pathology and Genetics of Tumours of the Nervous System. IARC Press, Lyon 2000; 172-174.

41. Woodruff JM, Perino G. Non-germ-cell or teratomatous malignant tumors showing additional rhabdomyoblastic differentiation, with emphasis on the malignant triton tumor. Semin Diagn Pathol 1994; 11: 69-81. 